\title{
Hirose Yöntemi İle Finansal Marka Değerinin Hesaplanması: Borsa İstanbul Bankacılık Sektörü Uygulaması \\ (Financial Brand Value Calculation With Hirose Method: An Ampirical Analysis in Istanbul Stock Exchange)
}

\author{
Sevilay USLU DİVANOĞLU (iD a , Haşim BAĞCI iD b , Mustafa EROĞLU iD c \\ a Aksaray Üniversitesi İktisadi ve İdari Bilimler Fakültesi İşletme Bölümü, Aksaray, Türkiye, sevilayuslu@yahoo.com \\ b Aksaray Üniversitesi Sağlık Bilimleri Fakültesi Sağlık Yönetimi Bölümü, Aksaray, Türkiye, hasimbagci1907@hotmail.com \\ c Akbank T.A.Ş. Operasyon Yöneticisi, $\underline{\text { mustafaeroglu@windowslive.com }}$
}

\begin{tabular}{|c|c|}
\hline MAKALE BİLGİSİ & ÖZET \\
\hline $\begin{array}{l}\text { Anahtar Kelimeler: } \\
\text { Marka Değeri } \\
\text { Bankacıllk Sektörü } \\
\text { Hirose Yöntemi } \\
\text { Brand Finance }\end{array}$ & $\begin{array}{l}\text { Amaç - Bu çalışmada hem pazarlama hem finans alanına hitap eden marka değeri ölçümü } \\
\text { hedeflenmiştir. Marka kavramı, hem işletmeler hem de tüketiciler açısından önemli bir konuma } \\
\text { sahiptir. Marka; işletmelerin ürünlerinin tüketici gözünde belirleyici olmasını sağlarken, tüketiciler } \\
\text { açısından da karar verme ve satın alma sürecinde en önemli faktörlerden birisini oluşturmaktadır. } \\
\text { Bu nedenle marka, günümüzde giderek artan bir finansal değere sahip olarak işletmelerin } \\
\text { aktiflerinde maddi olmayan duran varlık olarak yerini almaktadır. }\end{array}$ \\
\hline Gönderilme Tarihi 19 Haziran & $\begin{array}{l}\text { Yöntem - Çalışmada marka değeri ölçümü yapabilmek için Hirose yöntemi kullanılmış ve Hirose } \\
\text { yöntemiyle elde edilen sonuçlar Brand Finance raporlarıla karşılaştırılmıştır. }\end{array}$ \\
\hline $\begin{array}{l}2019 \\
\text { Revizyon Tarihi } 1 \text { Kasım } 2019 \\
\text { Kabul Tarihi } 15 \text { Kasım } 2019\end{array}$ & $\begin{array}{l}\text { Bulgular - Çalışmada Hirose yöntemiyle marka değeri hesaplaması, bankacılık sektörü için } \\
\text { yapılmıştır. Bankacılık sektöründe 2014-2018 yılları arası } 5 \text { yıllık zaman diliminde Borsa İstanbul'a } \\
\text { kayıtlı bankalar araştırmanın örneklemini oluşturmaktadır. Analiz sonucunda; Hirose yöntemine } \\
\text { göre finansal marka değeri en iyi banka Garanti Bankası, en kötü banka ise Türkiye Kalkınma } \\
\text { Bankası'dır. Brand Finance raporuna göre ise marka değeri en yüksek banka Akbank, en düşük } \\
\text { banka Türkiye Sınai Kalkınma Bankası'dır. }\end{array}$ \\
\hline & $\begin{array}{l}\text { Tartışma - Sonuçlar kapsamında marka değeri hesaplamasında birçok yöntemin olduğu ancak } \\
\text { yöntemlerin birbirinden farklı sonuçlar verebildiği saptanmıştır. Hirose yöntemi sonuçları ile Brand } \\
\text { Finance raporlarının birbirine yakın olsa da tamamen aynı olmadı̆̆ı tespit edilmiştir. Temel sebep } \\
\text { ise Hirose yönteminin finansal tablo verileri ile hesaplanması, Brand Finance raporlarının firmaların } \\
\text { finansal verilerinin yanı sıra tüketici davranışlarını da içermesidir. Çalışmanın özgünlügü ise hem } \\
\text { Hirose yönteminin bankacılık sektöründe henüz kullanılmaması hem de bankacılık sektörü için } \\
\text { Brand Finance raporlarına göre marka değeri yorumlamanın yetersiz olduğunun Hirose analizi } \\
\text { sonucu belirlenmesidir. Literatüre katkı sağlayan Hirose yönteminin tercih edilmesinin nedeni ise } \\
\text { hem sayısal verilerle çalışarak sağlıklı sonuçlara ulaşmak hem de sübjektif yargılardan uzak } \\
\text { olmaktır. }\end{array}$ \\
\hline
\end{tabular}

\begin{tabular}{|c|c|}
\hline ARTICLE INFO & ABSTRACT \\
\hline Keywords: & Purpose - In this study, it is aimed to measure brand value that addresses both marketing and \\
\hline Brand Value & finance. The brand concept has an important position for both businesses and consumers. Brand; \\
\hline Banking Sector & While making the products of the enterprises determinant in the eyes of the consumers, it is one of \\
\hline Hirose Method & the most important factors in the decision-making and purchasing process for consumers. For this \\
\hline Brand Finance & $\begin{array}{l}\text { reason, the brand has an increasing financial value and is now included in the assets of enterprises } \\
\text { as an intangible asset. Hirose method, which contributes to the literature, is preferred both to reach }\end{array}$ \\
\hline Received 19 June 2019 & healthy results by working with numerical data and to be away from subjective judgments. \\
\hline Revised 1 November 2019 & Design/methodology/approach - Çalışmada marka değeri ölçümü yapabilmek için Hirose yöntemi \\
\hline Accepted 15 November 2019 & kullanılmış ve Hirose yöntemiyle elde edilen sonuçlar Brand Finance raporlarıyla karşılaştırılmıştır. \\
\hline \multirow[t]{2}{*}{$\begin{array}{l}\text { Article Classification: } \\
\text { Research Article }\end{array}$} & $\begin{array}{l}\text { Findings - In the study, the brand value calculation by Hirose method was made for the banking } \\
\text { sector. The sample of the research is the banks registered in Istanbul Stock Exchange for } 5 \text { years in } \\
\text { the banking sector between 2014-2018. As a result of the analysis; financial brand value based to } \\
\text { Hirose method, while Garanti Bank is the best bank, Development Bank of Turkey is the worst bank. } \\
\text { According to the Brand Finance report; Akbank is the highest brand value while Industrial } \\
\text { Development Bank of Turkey is the lowest brand value. }\end{array}$ \\
\hline & $\begin{array}{l}\text { Discussion - Within the scope of the results, it was found that there are many methods in the } \\
\text { calculation of brand value, but the methods can give different results. The results of Hirose method }\end{array}$ \\
\hline
\end{tabular}


and Brand Finance reports were similar but not identical. The main reason is that while Hirose method is calculated with financial statement data, Brand Finance reports include consumer behavior as well as financial data of firms. The originality of the study is that both Hirose method is not used in the banking sector and it is determined by the Hirose analysis that the brand value interpretation in the Brand Finance reports is insufficient for the banking sector.

\section{GİRIŞ}

Marka ve marka değeri kavramları; rekabetin gittikçe arttığı ekonomik ortamda, hem tüketiciler hem de işletmeler açısından giderek daha fazla öneme sahip olmaktadır. Yakın geçmişte, 1980'li yıllardan itibaren marka değerinin önemi artmış ve firmaların büyüme amaçlı satın alımları ya da rakip firmaları satın almalarında ekonomik bir değer olarak kendini göstermeye başlamıştır (Alsu ve Palta, 2017: 176).

Hem tüketici davranışlarında etkin öneme sahip olması hem de işletmelerin ürünlerinin piyasada rekabetçi, tanınan ve tercih edilen bir özelliğe sahip olması açısından marka değerinin ölçümlenmesi ihtiyacı neticesinde çeşitli yöntemler geliştirilmiştir. Bu yöntemler finansal, davranışsal (tüketici temelli) ve karma yöntemlerdir.

Japonya Ekonomi Ticaret ve Endüstri Bakanlığı nezdinde yapılan çalışmalar neticesinde 2002 yılından itibaren uygulanmaya başlanan Hirose Metodu ile kamuya açık firma finansal verileri kullanılarak firmaların marka değerleri hesaplanabilmektedir (Uygurtürk vd., 2017: 15). Bu çalışmada, nicel verilerin kullanıldığı Hirose Yöntemi kullanılarak, payları Borsa İstanbul'da işlem gören 13 bankanın marka değerleri, ilgili bankaların Kamuyu Aydınlatma Platformu'nda (KAP) paylaştıkları finansal bilgileri ile hesaplanmıştır.

\section{MARKA DEĞERİ}

Marka değeri Aaker modeline göre; marka farkındalığı, sadakati ve markanın yaptığı çağrışımların bir kombinasyonudur (Aaker, 2018).

Özellikle 1980'li yıllarda artan şirket satın almaları ve devir faaliyetlerinde ortaya çıkan yüksek tutarlar, şirketlerin defter değerleri hesaplanırken, maddi olmayan duran varlık olan markanın finansal değerinin ölçümlenmesini ve hesaplanmasını gerektirmiştir (Alsu ve Palta, 2017: 176).

Firmaların sahibi oldukları markanın değeri bazı durumlarda firmanın sahip olduğu varlıklardan daha fazla olabilmektedir. Marka değerinin doğru olarak ölçülebilmesi ve mali tablolara yansıtılabilmesi yapılacak planlamalarda oldukça önemlidir (Akgün ve Akgün, 2014: 4).

Marka değeri olarak literatürde birbirlerinin yerine sıklıkla kullanılan ancak farklı anlamlar ifade eden 2 kavram mevcuttur. Tüketicilerde oluşan marka değeri algısını ifade etmek için "brand equity" kullanılırken, finansal yönden marka değerini ifade etmek için "brand value" terimleri kullanılmaktadır (Demir, 2016: 18).

Bunlara bağlı olarak marka değeri tespitinde de tüketici davranışları bazlı, finansal bazlı yaklaşımlarla analizler yapılmaktadır. Bununla birlikte her iki yöntemin bazı özelliklerini temel alarak geliştirilen karma yöntemler de bulunmaktadır (Zengin ve Güngördü, 2013: 286).

\section{Finansal Marka Değeri}

Finansal yöntemlerle marka değerinin hesaplanması, esas olarak markanın parasal değerini belirleme amacı gütmektedir (Demir, 2016: 29). Bu yaklaşım 3 farklı yöntem çerçevesinde ele alınmaktadır. Bunlar; maliyet temelli yöntemler, piyasa temelli yöntemler, gelir temelli yöntemlerdir (Uygurtürk vd., 2017: 13).

\section{Maliyet Tabanlı Yaklaşım}

$\mathrm{Bu}$ yaklaşım biçiminde, marka değeri hesaplanmak istenen firmanın, ilgili marka için geçmişten itibaren yaptığı harcamaların toplam maliyeti temel alınmakta veya o markanın yeniden oluşturulması için katlanılacak maliyetin hesaplanması yöntemi uygulanmaktadır. Geçmişe dönük maliyetlerin hesaplanması gerektiğinden, kuruluşu eski tarihlere dayalı firmaların marka değerlerinin hesaplanması oldukça güçtür (Akgün ve Akgün, 2014: 6).

\section{Piyasa Temelli Yöntemler}

Karşılaştırma yöntemi ile marka değeri bilinen firma verilerinin kullanılarak marka değeri bulunmak istenilen firma finansal verilerinin mukayese edilmesi yöntemidir (Özkan ve Terzi, 2012: 90). 


\section{Gelir Temelli Yöntemler}

Markanın ait olduğu firmaya gelecekte kar sağlayacağı ilkesinden hareket ederek markanın gelecekte sağlayacağı getirileri temel almaktadır. Marka değerinin sağlayacağı nakit akışı tahmin edilerek, bugünkü değere uygun bir iskonto oranı ile indirgenmekte ve marka değeri hesaplanmaktadır. Bu çalışmada gelir temelli bir yöntem olan Hirose yöntemi kullanılmıştır.

\section{Karma Yöntemler}

Finansal bazlı marka değerleme yöntemleri ile tüketici bazlı marka değerleme yöntemlerinin güçlü yönlerinin alınarak zaaflarının ortadan kaldırılması amaçlanarak geliştirilen yöntemlerdir (Çelik, 2006: 200).

$\mathrm{Bu}$ yöntemler akademik olarak değil, finans ve pazarlama konularında araştırma ve danışmanlık yapan şirketler tarafından geliştirilen yöntemlerdir. Hangi verilerin ne şekilde kullanıldığı bilinmemekle birlikte elde edilen marka değerleri dışında yöntemler hakkında bilgi paylaşılmamaktadır. Bu yöntemlerden Brand Finance yöntemi ile hesaplanarak firmaların kamuoyu ile paylaşılan marka değerleri karşılaştırma için kullanılmıştır.

\section{LITERATÜR İNCELEMESI}

Literatürde son yıllarda yerini alan bir yöntem olan Hirose yöntemi marka değeri hesaplanmasında kullanılmakta olup bankacılık sektörü için Hirose yönteminin kullanımı literatüre katkı sağlayan oldukça farklı bir araştırmadır. Marka değeri hesaplamasıyla ilgili literatürdeki çalışmalar ve Hirose yönteminin kullanıldığı araştırmalar hakkında kronolojik olarak bilgi verilmiştir.

Burmann, Benz \& Riley (2009) araştırmalarında; marka değeri modeli üretmeye çalışmışlardır. Yaptıkları kaynak araştırmalarının ardından marka değeri ölçümü için yönetim ve finans odaklı yeni bir marka değeri yaklaşımı geliştirmeyi amaçlamışlardır. Geliştirdikleri model kimlik temelli bir marka yönetimi yaklaşımını esas almaktadır. Modelin içerisine hem davranışsal hem de finansal faktörler yüklenerek ekonomik ölçüm yapmak kolaylaştırılmıştır. Modelin teorik altyapısı oluşturulup, marka değeri tanımı yapıldıktan sonra kimliğe dayalı marka modelinin gelecekteki araştırmalarda kullanılabilirliği sağlanmıştır.

Oliveira, Silvera \& Luce (2015) çalışmalarında; Brezilya'da telekomünikasyon sektörü için yeni model geliştirmişlerdir. Model; tüketici temelli marka değeri ile finansal temelli marka değerinin birleşiminden oluşmaktadır. Bu model; tüketicilerin satın alma davranışları bağlamında marka değişme olasılığını ve gelecek nakit akışları yardımıyla markanın finansal değerini hesaplamaktadır. Ayrıca firma rekabetini kontrol edebilmek için marka performans kıyaslaması ve finansal getiri tahmini yapmaktadır. Geliştirilen bu model, marka özsermaye modeli olarak literatürde yerini almıştır.

Zengin \& Güngördü (2015) marka değerini pazarlama ve finansa göre ayrı ayrı ölçerek kıyaslama yapmışlardır. Bu ölçüm için gıda sektörü işletmeleri kullanılmıştır. Finans açısından Hirose yöntemiyle marka değeri ölçümü yapılmış ve marka değeri sıralaması: Migros, BİM, CarrefourSA, Kiler ve Kipa biçiminde oluşmuştur. Pazarlama açısından ise anket yöntemi uygulanmış ve marka değeri sıralaması: Migros, CarrefourSA, BİM, Kipa ve Kiler şeklinde oluşmuştur. Çalışmanın sonucunda; finans ve pazarlama alanında kullanılan yaklaşımların birbirine yakın sonuçlar verdiği ortaya konmuştur.

Min Wang \& Kuang Yu (2015) bulanık mantık yaklaşımı ile Hirose yöntemini kullanarak marka değerlerini modellemeye çalışmışlardır. Bankacılık sektöründe yapılan bu çalışmada Tayvan'da bulunan bankaların marka değerleri incelenmiştir. Elde edilen sonuçlarda, bulanık mantığın ve hirose yönteminin, marka değerinin bulunmasında benzer yaklaşımlar gösterdiğini tespit etmişlerdir.

Majerova \& Kliestik (2015) Slovakya'da kullanılabilecek marka değerleme yöntemlerinin analizini yapmışlardır. Analizler sonucunda; Slovakya'da marka değerlemesi için en uygun modelin Hirose yöntemi olduğunu belirlemişlerdir.

Wang \& Sengupta (2016) yayınlarında; hissedarlar, firma performansı ve kurumsal marka değeri ilişkisi incelenmiştir. Araştırmada kaynak temelli teori kullanılmış ve hissedarlar ile firma ilişkilerinin kurumsal marka değerini ve firma performansını artırdığını öneren bir model geliştirmiştir. Analizde 2005-2008 yılları arası 282 firma incelenmiştir. Sonuç olarak; marka değeri ile pay sahipleri arasında pozitif bir ilişki saptanmıştır. Hatta marka değeri, pay sahipleri ile performans arasındaki bağlantının aracısıdır. 
Alper \& Aydoğan (2017) 2009 ve 2016 yılları arasında BİST metal eşya, makine ve gereç yapım sektöründeki 17 firmanın finansal performansları ve marka değerleri arasında ilişki kurmaya çalışmışlardır. Araştırmaya konu firmaların marka değerleri Hirose yöntemi kullanılarak hesaplanmış, firmaların marka değerleri ile finansal performansları arasında anlamlı bir ilişki olduğu sonucu elde edilmiştir.

Fischer \& Himme (2017) finans ve pazarlamanın birleşimiyle oluşan değer yaratmak için bir model geliştirmişlerdir. Geliştirilen model; reklam vb. yatırımların borçlanma ve kredi dağılımı üzerindeki etkisiyle finansal kaynak seviyesini arttıran müşteri bazlı marka değerini nasıl yükselttiğini önermektedir. 2005-2012 yılları arası 155 firmanın Harris EquiTrend verilerine göre ölçüm yapılmıştır. Araştırmanın sonucunda; bu ölçümün yetersiz olduğu saptanmış ve sağlıklı değerlendirme yapabilmek için pazarlama ve finans yöneticilerinin performans ve karar vermede etkin rol oynayan faktörlerin dinamik etkileşimlerini dikkate almaları gerekmektedir.

\section{ARAŞTIRMANIN YÖNTEMI}

Dr. Yoshikuni Hirose başkanlığında 2002 yılında hazırlanan çalışma ile firmaların marka değerleri, kamuya açık finansal raporlarındaki veriler ile hesaplanabilmektedir. Yöntemde marka değeri; prestij değişkeni, sadakat değişkeni, genişleme değişkeni ve risksiz faiz oranının bir fonksiyonu şeklinde ifade edilmektedir (Başç1, 2009: 74).

MD : Marka Değeri

PD : Prestij Değişkeni

$\mathrm{SD}:$ Sadakat Değişkeni

GD : Genişleme Değişkeni

rf: Risksiz Faiz Oranı

$$
\mathrm{MD}=\frac{\mathrm{PD} \cdot \mathrm{SD} \cdot \mathrm{GD}}{r_{f}}(1)
$$

\section{Prestij Değişkeni}

Markaya dayanan fiyat avantajının tespit edilmesi için kullanılmaktadır. Bu avantaj, firmanın, rakiplerine kıyasla daha yüksek bir fiyattan ürün ya da hizmet satmasına imkan vermektedir. Prestij değişkeni hesaplanırken kullanılan değerler, sektördeki en düşük karlılık oranına sahip firma değerleri ile karşılaştırılmaktadır (Başçı, 2009: 75).

$$
\mathrm{PD}=\frac{1}{5} \sum_{i=-4}^{0}\left[\left(\frac{S_{i}}{S M M_{i}}-\frac{S_{i}^{*}}{S M M_{i}^{*}}\right) \times \frac{R P G_{i}}{F G_{i}}\right] \times S M M_{0}(2)
$$

PD : Prestij Değişkeni

$S:$ Satışlar

SMM : Satılan malın maliyeti

$\mathrm{Si}^{*}$ : Karşılaştırılan firmanın satışları

$\mathrm{SMMi}^{*}$ : Karşılaştırılan firmanın satılan malın maliyeti

RPG : Reklam ve promosyon giderleri

FG : Faaliyet giderleri

\section{Sadakat Değişkeni}

Satılan malın maliyet değerlerindeki istikrarın ölçümlenmesine dayanmaktadır (Bursalı, 2005: 292).

$$
S D=\frac{\mu_{c}-\sigma_{c}}{\mu_{c}}(3)
$$

SD : Sadakat Değişkeni

$\mu_{\mathrm{c}}$ : Satılan malın maliyetinin son 5 yıllık ortalaması

$\sigma_{c}:$ Satılan malın maliyetinin standart sapması 


\section{Genişleme Değişkeni}

Firmanın son 2 yıldaki yurtdışı satışları ile faaliyet dışı giderlerinin tespit edilmesi ile elde edilmektedir.

$$
G D=\frac{1}{2}\left\{\frac{1}{2} \sum_{i=-1}^{0}\left(\frac{S O_{i}-S O_{i-1}}{S O_{i-1}}+1\right)+\frac{1}{2} \sum_{i=-1}^{0}\left(\frac{S X_{i}-S X_{i-1}}{S X_{i-1}}+1\right)\right\}(4)
$$

$\mathrm{SO}:$ Firmanın yurt dışı satışları

SX : Firmanın ana faaliyet konusu dışındaki gelirleri

Yöntemde prestij, sadakat ve genişleme değişkenleri hesaplandıktan sonra bu değerlerin çarpımı risksiz faiz oranına (marka değeri hesaplandığı tarihteki devlet tahvili/hazine bonosu faiz oranı) bölünmesi ile marka değeri elde edilmektedir (Akgün ve Akgün, 2014: 8).

\subsection{Araştırmanın Örneklemi ve Veri Seti}

2018 Yılı itibariyle payları Borsa İstanbul nezdinde işlem gören ve bankacılık sektöründe faaliyet gösteren işletmeler Tablo 1'de gösterilmiştir.

Tablo 1. BIST Bankacıllk Sektöründe Faaliyet Gösteren Şirketler

\begin{tabular}{|c|l|l|}
\hline Sira & \multicolumn{1}{|c|}{ Kod } & \multicolumn{1}{c|}{ Şirket Unvanı } \\
\hline 1 & AKBNK & AKBANK T.A.Ş. \\
\hline 2 & ALBRK & ALBARAKA TÜRK KATILIM BANKASI A.Ş. \\
\hline 3 & DENIZ & DENİZANK A.Ş. \\
\hline 4 & ICBCT & ICBC TURKEY BANK A.Ş. \\
\hline 5 & QNBFB & QNB FİNANSBANK A.Ş. \\
\hline 6 & SKBNK & ŞEKERBANK T.A.Ş. \\
\hline 7 & GARAN & TÜRKIYY GARANTI BANKASI A.Ş. \\
\hline 8 & HALKB & TÜRKIYYE HALK BANKASI A.Ş. \\
\hline 9 & ISATR/B/C/K & TÜRKIYYE İŞ BANKASI A.Ş. \\
\hline 10 & KLNMA & TÜRKİYE KALKINMA VE YATIRIM BANKASI A.Ş. \\
\hline 11 & TSKB & TÜRKİYE SINAİ KALKINMA BANKASI A.Ş. \\
\hline 12 & VAKBN & TÜRKİYE VAKIFLAR BANKASI T.A.O. \\
\hline 13 & YKBNK & YAPI VE KREDİ BANKASI A.Ş. \\
\hline
\end{tabular}

Tablo 1'e göre; hisseleri halka arz edilmiş, halka açık ve borsaya kote olmuş 13 banka bulunmaktadır. Bu bankaların verileri kamuyu aydınlatma platformunda yer almaktadır. Çalışmada 2014-2018 yılları arasındaki 5 yıllık bilanço ve gelir tablolarından elde edilen veri seti Tablo 2' de gösterilmiştir.

Tablo 2. Hesaplamalarda Kullanılan Değişkenler ve Bulundukları Mali Tablolar

\begin{tabular}{|c|c|}
\hline Bilanço ve Gelir Tablosu Kalemleri & Verinin Alındı̆̆ı Tablo \\
\hline Faiz Gelirleri & Gelir Tablosu \\
\hline Ücret ve Komisyon Gelirleri & Gelir Tablosu \\
\hline Faiz Giderleri & Gelir Tablosu \\
\hline Diğer Faaliyet Gelirleri & Gelir Tablosu \\
\hline Diğer Faaliyet Giderleri & Gelir Tablosu \\
\hline Türev Finansal İşlemler & Gelir Tablosu \\
\hline Kambiyo İşlemleri & Gelir Tablosu \\
\hline Reklam Ve Promosyon Giderleri & Dipnotlar \\
\hline
\end{tabular}

Tablo 2' de bankaların marka değerini hesaplamak için kullanılan değişkenler ve bu değişkenlerin hangi mali tablolardan alındığı sunulmuştur. Bankalara ait mali tablolara KAP internet sitesinden erişilmiştir. 


\subsection{Modelin Kapsamı ve Sinırlılıkları}

Model kapsamında Borsa İstanbul Bankacılık sektöründe işlem gören 13 bankanın 2014-2018 yılları arası 5 yıllık verileri incelenmiştir. Hirose yönteminde bulunan prestij değişkeninin hesaplanmasında kullanılan satış tutarları, satılan malın maliyeti ve faaliyet giderleri kalemleri bankalara ait mali tablolarda yer almamaktadır. Bankalar fiziksel bir üretim yapmamakta ve mali hizmet sunarak faiz ve komisyon karı elde etmektedir. Bu nedenle, hesaplamalarda satışlar değişkeni olarak banka mali tablolarında bulunan faiz gelirleri kalemi ile ücret ve komisyon gelirleri kalemlerindeki tutarlar toplamı kullanılmıştır. Bankalarda fiziki bir üretim gerçekleşmediğinden mali tablolarda satılan malın maliyeti kalemi de yer almamaktadır. Faiz giderleri, bankanın piyasadan topladığı mevduatlara vermiş olduğu faizin toplam tutarı yani maliyetidir. Bu nedenle; satılan malın maliyeti değişkeni olarak banka mali tablolarında bulunan faiz giderleri değerleri esas alınmıştır. Faaliyet giderleri değişkeni olarak ise mali tablolarda bulunan diğer faaliyet giderleri verileri kullanılmıştır. Banka bilançolarında ana faaliyet konusu dışındaki gelirler kalemi bulunmamaktadır. Bu değişken için mali tablolarda bulunan diğer faaliyet gelirleri tutarları temel alınmıştır. Yurt dışı satışlar kalemi de banka mali tablolarında yer almamaktadır. Mali tablolarda yer alan türev finansal işlemler ve kambiyo işlemleri döviz bazında gerçekleşmekte ve bankaların yurtdışı döviz işlemlerinin esasını oluşturmaktadır. Bu nedenle, yurt dışı satışlar değişkeni olarak mali tablolarda bulunan türev finansal işlemler ile kambiyo işlemleri tutarlarının toplamı alınmıştır.

Hirose yönteminde kullanılan genişleme değişkeni hesaplamasında son 3 yıla ait yurt dışı satış tutarları ve ana faaliyet konusu dışındaki gelir değerleri kullanılmaktadır. Hesaplamalarda kullanılan 13 adet bankanın bu verileri incelendiğinde; Vakıflar Bankası A.O verileri haricinde diğer 12 bankaya ait yurt dışı satış değerleri negatif çıkmaktadır. 2015-2018 yılları içerisinde 10 adet bankanın negatif yurt dışı satış ortalaması değeri bulunmakta olup bu negatif değerler genişleme değişkeni hesaplamalarına dahil edilememiştir. Objektif bir değerlendirme yapılabilmesi için Vakıflar Bankası A.O. ile Albaraka Türk Katılım Bankası A.Ş. mali tablolarında bulunan yurt dışı satış değerleri de, genişleme değişkeni hesaplamasına dahil edilmemiştir. Hesaplamanın tutarlı olması için genişleme değişkeni formülü aşağıdaki şekilde yeniden düzenlenmiştir.

$$
G D=\frac{1}{2} \sum_{i=-1}^{0}\left(\frac{S X_{i}-S X_{i-1}}{S X_{i-1}}+1\right)(5)
$$

Belirtilen kısıtlar nedeni ile Hirose yöntemindeki formüllerde kullanılan değişkenler Tablo 3'de gösterilmiştir.

Tablo 3. Hirose Yöntemi Hesaplamalarına Göre Mali Tablo Değerleri

\begin{tabular}{|c|c|}
\hline Hirose yönteminde kullanılan değişken & Mali tabloda eşleştirilen değer kalemi \\
\hline Satışlar & Faiz Gelirleri + Ücret ve Komisyon Gelirleri \\
\hline Satılan Malın Maliyeti & Faiz Giderleri \\
\hline Faaliyet Giderleri & Diğer Faaliyet Giderleri \\
\hline Ana Faaliyet Konusu Dışındaki Gelirleri & Diğer Faaliyet Gelirleri \\
\hline Yurt Dışı Satışlar & Türev Finansal İşlemler + Kambiyo İşlemleri \\
\hline
\end{tabular}

Tablo 3' de bankacılık sektörünün farklı bilanço ve gelir tablosu içermesinden dolayı hangi kalemin hangi mali tablo kalemi ile eşleştirilerek hesaplandığı gösterilmiştir. Bu eşleşme tüm bankalar ve tüm yıllar için yapılmıştır.

\subsection{Bulgular}

Prestij Değerlerinin Hesaplanması

$$
\mathrm{PD}=\frac{1}{5} \sum_{i=-4}^{0}\left[\left(\frac{S_{i}}{S M M_{i}}-\frac{S_{i}^{*}}{S M M_{i}^{*}}\right) \times \frac{R P G_{i}}{F G_{i}}\right] \times S M M_{0}(6)
$$

PD : Prestij Değişkeni

$S:$ Satışlar

SMM : Satılan malın maliyeti

$\mathrm{S}^{*}$ : Karşılaştırılan firmanın satışları 
S. U. Divanoğlu - H. Bağc1 - M. Eroğlu 11/4 (2019) 2566-2577

$\mathrm{SMM}_{\mathrm{i}}^{*}$ : Karşılaştırılan firmanın satılan malın maliyeti

RPG : Reklam ve promosyon giderleri

FG : Faaliyet giderleri

Prestij değişkeni hesaplamasında; her firmanın her yıl için S/SMM oranı hesaplanarak aynı yılın sektördeki en küçük $\mathrm{S}^{*} / \mathrm{SMM}^{*}$ oranına sahip firma değeri ile karşılaştırılmaktadır. Yıllara göre en küçük $\mathrm{S}^{*} / \mathrm{SMM}^{*}$ oranına sahip firmalar ve oran değerleri Tablo 4'de verilmiştir.

Tablo 4. Yıllara Göre En Düşük Satışlar/Satılan Malın Maliyeti Rasyoları

\begin{tabular}{|l|c|c|}
\hline \multicolumn{1}{|c|}{ Banka Ad1 } & Yil & S*/SMM* Oranı \\
\hline TÜRKIYYE VAKIFLAR BANKASI A.O. & 2014 & 1,811959451 \\
\hline TÜRKIYYE VAKIFLAR BANKASI A.O. & 2015 & 1,801828781 \\
\hline TÜRKIYYE VAKIFLAR BANKASI A.O. & 2016 & 1,837659628 \\
\hline TÜRKIYYE HALK BANKASI A.Ş. & 2017 & 1,671342067 \\
\hline TÜRKIYYE HALK BANKASI A.Ş. & 2018 & 1,378286474 \\
\hline
\end{tabular}

Sektördeki en küçük $S^{*} / S_{M M} *$ oranları her yıla ait firma S/SMM değerinden çıkarılmıştır. Bulunan değer, firmanın o yıla ait RPG/FG oranı ile çarpılarak her yıla ait oranlar elde edilmiş ve bu oranlar toplanarak ortalaması alınmıştır. Ardından SMM değeri hesaplanmış ve Tablo 5'de görülmektedir.

Tablo 5. 2018 Yılı Satılan Malın Maliyeti değerleri (SMM0)

\begin{tabular}{|c|c|}
\hline Banka Adı & 2018 Yılı SMM Değeri - TL \\
\hline AKBANK TÜRK ANONİM ŞİRKETİ & 19.923 .670 € \\
\hline ALBARAKA TÜRK KATILIM BANKASI A.Ş. & $1.959 .225 €$ \\
\hline DENIZBANK A.Ş. & $10.841 .929 €$ \\
\hline ICBC TURKEY BANK A.Ş. & $764.529 €$ \\
\hline QNB FINANSBANK ANONIM ŞİRKETI & 9.306 .793 £ \\
\hline ŞEKERBANK TÜRK A.Ş. & $2.906 .150 €$ \\
\hline TÜRKIYYE GARANTİ BANKASI A.Ş. & $20.369 .094 €$ \\
\hline TÜRKIYYE HALK BANKASI A.Ş. & $28.674 .763 €$ \\
\hline TÜRKIYYE İŞ BANKASI A.Ş. & $24.492 .384 €$ \\
\hline TÜRKIYE KALKINMA BANKASI A.Ş. & $232.346 €$ \\
\hline TÜRKIYE VAKIFLAR BANKASI TÜRK A.O. & $23.529 .737 €$ \\
\hline TÜRKIYYE SINAİ KALKINMA BANKASI A.Ş. & $1.381 .391 €$ \\
\hline YAPI VE KREDİ BANKASI A.Ş. & $21.011 .923 €$ \\
\hline Sektör Toplamı & 165.393.934 E \\
\hline
\end{tabular}

Tablo 5'e göre; formüldeki SMM değeri, marka değeri bulunmak istenen yılın gelir tablosu değeri olup her yıl için sabittir. SMM değeri yardımıyla bulunan prestij değerleri ise Tablo 6 ' da gösterilmiştir.

Tablo 6. Firmalara Ait Prestij Değişkeni Değerleri

\begin{tabular}{|c|c|}
\hline Banka Adı & Prestij Değişkeni \\
\hline AKBANK TÜRK ANONIM ŞíRKETİ & $462.197 .296,68$ \\
\hline ALBARAKA TÜRK KATILIM BANKASI A.Ş. & $11.570 .715,72$ \\
\hline DENIZBANK A.Ş. & $181.058 .951,71$ \\
\hline ICBC TURKEY BANK A.Ş. & $1.352 .822,37$ \\
\hline QNB FİNANSBANK ANONİM ŞİRKETİ & $255.127 .485,74$ \\
\hline ŞEKERBANK TÜRK A.Ş. & $25.466 .711,84$ \\
\hline
\end{tabular}


S. U. Divanoğlu - H. Bağc1 - M. Eroğlu 11/4 (2019) 2566-2577

\begin{tabular}{|c|c|}
\hline TÜRKIYE GARANTI BANKASI A.Ş. & $465.557 .363,47$ \\
\hline TÜRKIYY HALK BANKASI A.Ş. & $77.378 .429,13$ \\
\hline TÜRKIYY İŞ BANKASI A.Ş. & $279.356 .817,44$ \\
\hline TÜRKIYY KALKINMA BANKASI A.Ş. & $832.867,23$ \\
\hline TÜRKIYY VAKIFLAR BANKASI TÜRK A.O. & $213.805 .216,43$ \\
\hline TÜRKIYYE SINAİ KALKINMA BANKASI A.Ş. & $12.025 .238,30$ \\
\hline YAPI VE KREDİ BANKASI A.Ş. & $252.118 .172,44$ \\
\hline
\end{tabular}

Son işlem olarak marka değeri bulunmak istenilen yıldaki satılan malın maliyeti olan SMM değeri ile çarpılarak prestij değerleri elde edilmiştir.

\section{Sadakat Değişkeninin Hesaplanması}

$$
S D=\frac{\mu_{c}-\sigma_{c}}{\mu_{c}}(7)
$$

SD : Sadakat Değişkeni

$\mu_{\mathrm{c}}$ : Satılan malın maliyetinin son 5 yıllık ortalaması

$\sigma_{c}$ : Satılan malın maliyetinin standart sapması

Firmalara ait standart sapma değerlerinin bulunması hassasiyeti ve güvenilirliği açısından Excel STDSAPMA fonksiyonu ile yapılmıştır. Bulunan standart sapma değerleri ve sadakat değişkenleri Tablo 7 'de verilmiştir.

Tablo 7. Standart Sapma ve Sadakat Değişkeni Değerleri

\begin{tabular}{|c|c|c|c|}
\hline Banka Adı & SMM 5 Yillık Ortalama & Standart Sapma Değerleri & Sadakat Değişkenleri \\
\hline AKBANK TÜRK ANONIM ŞİRKETİ & $11.845 .636 €$ & 5016561,053 & 0,576505561 \\
\hline ALBARAKA TÜRK KATILIM BANKASI A.Ş. & $1.276 .233 €$ & 436258,2845 & 0,658167158 \\
\hline DENIZBANK A.Ş. & $6.026 .868 €$ & 2919943,658 & 0,515512244 \\
\hline ICBC TURKEY BANK A.Ş. & $341.916 €$ & 251834,0295 & 0,263462285 \\
\hline QNB FINANSBANK ANONIM ŞİRKETİ & $5.300 .195 €$ & 2380938,343 & 0,550782861 \\
\hline ŞEKERBANK TÜRK A.Ş. & $903.968 €$ & 124124,6673 & 0,862689061 \\
\hline TÜRKIYYE GARANTİ BANKASI A.Ş. & $12.048 .023 €$ & 4974430,009 & 0,587116505 \\
\hline TÜRKIYYE HALK BANKASI A.Ş. & $13.684 .464 €$ & 9027254,753 & 0,340328237 \\
\hline TÜRKIYY İş BANKASI A.Ş. & 14.780.519€ & 6002413,033 & 0,593897016 \\
\hline TÜRKIYYE KALKINMA BANKASI A.Ş. & $91.391 €$ & 82323,82034 & 0,099211077 \\
\hline TÜRKIYYE VAKIFLAR BANKASI TÜRK A.O. & $12.275 .781 €$ & 6707437,922 & 0,453603986 \\
\hline TÜRKIYYE SINAİ KALKINMA BANKASI A.Ş. & $694.280 €$ & 82323,82034 & 0,345821672 \\
\hline YAPI VE KREDİ BANKASI A.Ş. & 12.186.920€ & 5491555,867 & 0,549389371 \\
\hline
\end{tabular}

\section{Genişleme Değişkeni Hesaplanması}

Modelin kapsamı ve sınırlılıkları kısmında da belirtildiği gibi, yurtdışı satışlar değişkeni için gelir tablosundan alınan türev işlemler ve kambiyo işlemleri toplam tutarları, sektördeki 13 bankanın 12'sinde negatif değere sahip olduğundan, objektif bir değerlendirme sağlamak üzere yurtdışı satışlar değişkeni ihmal edilmiş ve buna bağlı formül hesaplanmamıştır. Yurtdışı satışlar değişkeni ve faaliyet konusu dışındaki gelirler değişkeni ile yapılacak hesaplamada, son 3 yıla ait değerler toplamı tutarlarının, her toplam işleminden sonra yarısı alınmakta, sonrasında yurtdışı satışlar toplamından elde edilen değer ve faaliyet konusu dışındaki satışlar toplamından elde edilen değer de toplanarak yarısı alınmaktadır.

Formülde, yurtdışı satışlar değişkeni ihmal edildiğinden, formülün son kısmında ortalama alınmasını sağlayan bölme işlemi de ihmal edilerek formül aşağıdaki şekilde sadeleştirilmiştir.

$$
G D=\frac{1}{2} \sum_{i=-1}^{0}\left(\frac{S X_{i}-S X_{i-1}}{S X_{i-1}}+1\right)(8)
$$

Sadeleştirilen formül ile yapılan hesaplamalar neticesinde elde edilen genişleme değişkenleri Tablo 8'de 
gösterilmiştir.

Tablo 8. Genişleme Değişkeni Değerleri

\begin{tabular}{|c|c|}
\hline Banka Adı & Genişleme Değişkeni* $^{*}$ \\
\hline AKBANK TÜRK ANONIM ŞİRKETİ & 1,094508434 \\
\hline ALBARAKA TÜRK KATILIM BANKASI A.Ş. & 1,840947682 \\
\hline DENIZBANK A.Ş. & 0,785093429 \\
\hline ICBC TURKEY BANK A.Ş. & 1,58079158 \\
\hline QNB FINANSBANK ANONIM ŞiRKETI & 0,437860146 \\
\hline ŞEKERBANK TÜRK A.Ş. & 0,570820597 \\
\hline TÜRKIYE GARANTI BANKASI A.Ş. & 1,364964942 \\
\hline TÜRKIYY HALK BANKASI A.Ş. & 1,167708216 \\
\hline TÜRKIYYE İŞ BANKASI A.Ş. & 1,103665908 \\
\hline TÜRKİYE KALKINMA BANKASI A.Ş. & 1,547008531 \\
\hline TÜRKIYYE VAKIFLAR BANKASI TÜRK A.O. & 1,409047801 \\
\hline TÜRKIYYE SINAİ KALKINMA BANKASI A.Ş. & 2,081166664 \\
\hline YAPI VE KREDİ BANKASI A.Ş. & 1,586812943 \\
\hline
\end{tabular}

Not:* Yurt dışı işlemler için alınan Türev Finansal İşlemler ve Kambiyo İşlemleri değerleri negatif çıtığından hesaplanamamıştır.

Genişleme değişkeni, sadece Diğer Faaliyet Gelirleri değerleri ile hesaplanarak formül yeniden düzenlenmiştir.

\section{Modelin Sonuçları}

Hirose yönteminde kullanılan prestij, sadakat ve genişleme değişkenlerinin çarpımları alınarak risksiz faiz oranı $\mathrm{r}_{\mathrm{f}}$ ile iskonto edilmekte ve firmalara ait marka değerleri elde edilmektedir. Tablo $9^{\prime}$ da Hirose marka değerleri sunulmuştur.

Tablo 9. Elde Edilen Marka Değerleri

\begin{tabular}{|c|c|c|c|c|c|}
\hline Banka Adı & $\begin{array}{c}\text { Prestij } \\
\text { Değişkeni }\end{array}$ & $\begin{array}{c}\text { Sadakat } \\
\text { Değişkeni }\end{array}$ & $\begin{array}{l}\text { Genişleme } \\
\text { Değişkeni* }\end{array}$ & $r^{* *}$ & $\begin{array}{c}\text { Hirose } \\
\text { Marka Değeri - TL }\end{array}$ \\
\hline AKBANK TÜRK ANONIM ŞİRKETI & 462.197.296,68 & 0,576505561 & 1,09450843 & 0,1973 & 1.478.165.049,19€ \\
\hline ALBARAKA TÜRK KATILIM BANKASI A.Ş. & $11.570 .715,72$ & 0,658167158 & 1,84094768 & 0,1973 & 71.057.642,17£ \\
\hline DENIZBANK A.Ş. & 181.058.951,71 & 0,515512244 & 0,78509343 & 0,1973 & 371.409.701,30 £ \\
\hline ICBC TURKEY BANK A.Ş. & $1.352 .822,37$ & 0,263462285 & 1,58079158 & 0,1973 & 2.855.661,72€ \\
\hline QNB FINANSBANK ANONIM ŞİRKETI & 255.127.485,74 & 0,550782861 & 0,43786015 & 0,1973 & 311.850.180,12 € \\
\hline ŞEKERBANK TÜRK A.Ş. & $25.466 .711,84$ & 0,862689061 & 0,5708206 & 0,1973 & 63.562.316,38 € \\
\hline TÜRKIYYE GARANTİ BANKASI A.Ş. & $465.557 .363,47$ & 0,587116505 & 1,36496494 & 0,1973 & 1.891.001.621,92€ \\
\hline TÜRKIYYE HALK BANKASI A.Ş. & $77.378 .429,13$ & 0,340328237 & 1,16770822 & 0,1973 & $155.856 .580,62 £$ \\
\hline TÜRKIYE İŞ BANKASI A.Ş. & $279.356 .817,44$ & 0,593897016 & 1,10366591 & 0,1973 & 928.070.482,00 £ \\
\hline TÜRKIYE KALKINMA BANKASI A.Ş. & $832.867,23$ & 0,099211077 & 1,54700853 & 0,1973 & $647.890,42 €$ \\
\hline TÜRKIYYE VAKIFLAR BANKASI TÜRK A.O. & $213.805 .216,43$ & 0,453603986 & 1,4090478 & 0,1973 & 692.618.041,49£ \\
\hline TÜRKIYYE SINAİ KALKINMA BANKASI A.Ş. & $12.025 .238,30$ & 0,345821672 & 2,08116666 & 0,1973 & 43.865.761,45€ \\
\hline YAPI VE KREDİ BANKASI A.Ş. & $252.118 .172,44$ & 0,549389371 & 1,58681294 & 0,1973 & 1.113.994.513,93€ \\
\hline
\end{tabular}

Tablo 9'da; prestij, sadakat ve marka değişkeni hesaplandıktan sonra marka değeri hesaplanmıştır. Marka değeri hesaplanması için kullanılacak olan risksiz faiz oranı 31.12.2018 tarihli gösterge tahvilin faiz oranı \% 19.73'tür. Ardından Hirose formülü yardımıyla bankalar için Hirose marka değerleri bulunmuştur. Hirose marka değerlerine göre; en iyi marka değerine sahip banka Garanti Bankası iken Akbank ve Yapı Kredi sırasıyla diğer en iyi marka değeri olan bankalardır. Marka değeri en düşük olan banka ise Türkiye Kalkınma 
Bankasi'dır.

Hirose yöntemi ile elde edilen değerler 31.12.2018 tarihli USD kuru üzerinden hesaplanarak firmaların USD kuru ile marka değerleri, Brand Finance 2018 verileri ile karşılaştırmalı olarak Tablo 10'da verilmektedir.

Tablo 10. Hirose ve Brand Finance Marka Değerleri Karşılaştırması

\begin{tabular}{|c|c|c|c|}
\hline Banka Adı & $\begin{array}{c}\text { Hirose } \\
\text { Marka Değeri (TL) } \\
\end{array}$ & $\begin{array}{c}\text { Hirose } \\
\text { Marka Değeri (USD) } \\
\end{array}$ & $\begin{array}{l}\text { Brand Finance } 2018 \\
\text { Marka Değeri (USD) } \\
\end{array}$ \\
\hline AKBANK TÜRK ANONIM ŞİRKETI & 1.478.165.049,19ほ & $279.650 .957,61$ & $1.649 .000 .000,00$ \\
\hline $\begin{array}{l}\text { ALBARAKA TÜRK KATILIM } \\
\text { BANKASI A.Ş. } \\
\end{array}$ & 71.057.642,17€ & $13.443 .246,87$ & $103.000 .000,00$ \\
\hline DENIZBANK A.Ş. & 371.409.701,30€ & $70.266 .225,47$ & $347.000 .000,00$ \\
\hline ICBC TURKEY BANK A.Ş. & $2.855 .661,72 €$ & $540.256,67$ & $* * * *$ \\
\hline $\begin{array}{l}\text { QNB FINANSBANK ANONIM } \\
\text { ŞİRKETI }\end{array}$ & 311.850.180,12€ & $58.998 .284,09$ & $* * * *$ \\
\hline ŞEKERBANK TÜRK A.Ş. & $63.562 .316,38 €$ & $12.025 .221,85$ & $136.000 .000,00$ \\
\hline TÜRKIYE GARANTİ BANKASI A.Ş. & 1.891.001.621,92 छ & $357.754 .646,35$ & 1.584.000.000,00 \\
\hline TÜRKIYY HALK BANKASI A.Ş. & $155.856 .580,62 €$ & $29.486 .180,89$ & $757.000 .000,00$ \\
\hline TÜRKIYYE İŞ BANKASI A.Ş. & $928.070 .482,00 €$ & $175.579 .715,65$ & 1.334.000.000,00 \\
\hline $\begin{array}{l}\text { TÜRKIYE KALKINMA BANKASI } \\
\text { A.Ş. } \\
\end{array}$ & $647.890,42 €$ & $122.573,04$ & $* * * *$ \\
\hline $\begin{array}{l}\text { TÜRKIYE VAKIFLAR BANKASI } \\
\text { TÜRK A.O. }\end{array}$ & 692.618.041,49€ & $131.034 .960,32$ & $622.000 .000,00$ \\
\hline $\begin{array}{c}\text { TÜRKIYE SINAİ KALKINMA } \\
\text { BANKASI A.Ş. }\end{array}$ & 43.865.761,45€ & $8.298 .871,77$ & $66.000 .000,00$ \\
\hline YAPI VE KREDİ BANKASI A.Ş. & 1.113.994.513,93€ & $210.754 .294,84$ & $937.000 .000,00$ \\
\hline
\end{tabular}

Hirose yöntemi ile yapılan hesaplamalarda Garanti Bankası ve Akbank'ın ilk iki sırada yer aldığı, 3. sırada ise Yapı ve Kredi Bankası olduğu görülmekte iken Tablo 10 incelendiğinde; elde edilen marka değerleri ile Brand Finance marka değerleri arasında farklılıklar olduğu görülmektedir. Brand Finance raporuna göre ise en iyi marka değerine sahip banka Akbank, 2. sırada Garanti Bankası, 3. sırada ise İş Bankası yer almaktadır. Ayrıca Brand Finance raporuna göre en zayıf marka değeri ise Türkiye Sınai Kalkınma Bankası'na aittir. Ancak Brand Finance 2018 raporuna göre; ICBC Turkey Bank A.Ş., QNB Finansbank A.Ş. ve Türkiye Kalkınma Bankası A.Ş.'ye ait yayınlanan bir marka değeri bulunmamaktadır.

\section{SONUÇ}

Hirose yöntemi 2002 yılında Japonya Ekonomi Ticaret ve Endüstri Bakanlığı nezdinde yapılan çalışmalar neticesinde ortaya çıkarılmış, tamamen firma finansal verilerine dayalı bir marka değeri hesaplama yöntemidir. Bu hesaplama yönteminde; firma mali tablolarında bulunan ve son 5 yıla ait satışlar, satışların maliyeti, reklam ve promosyon giderleri, faaliyet giderleri, yurtdışı satışlar ve faaliyet dışı gelir değerleri kullanılmaktadır. Bu değerler ile elde edilen ve Hirose yönteminde kullanılan formülün çarpanlarından olan prestij değişkeni, sadakat değişkeni ve genişleme değişkeni, belli bir oran üzerinden (risksiz faiz oranı) iskonto edilerek firmanın marka değeri hesaplanabilmektedir. Finansal bilgileri kamuya açı olan hemen her şirketin marka değeri, tamamen nicel ve mali verilere dayandığından Hirose yöntemi ile rahatlıkla hesaplanabilmektedir.

Payları Borsa İstanbul'da işlem gören 13 bankaya ait mali tablo verileri kullanılarak marka değerlemede finansal yöntemlerden biri olan Hirose Yöntemi ile bankaların marka değerleri hesaplanmıştır. Yapılan çalışmada elde edilen değerler, Brand Finance'ın 2018 yılı marka değerlendirme raporunda bulunan marka değerleri ile karşılaştırılmıştır. Hirose yöntemi ile elde edilen marka değerleri ile Brand Finance marka değerleri birbirleri ile tutarsızdır. Bu durumun başlıca nedenleri; Hirose yönteminin tamamen firma mali tablo verilerine dayalı olması ve Brand Finance marka değeri yönteminin ise hem firma mali verilerine hem de tüketici davranışlarına dayalı bir yöntem olmasıdır.

Finansal yöntemle yapılan hesaplamalarda tüketicilerin davranışsal özellikleri, tercihleri ihmal edilmektedir. $\mathrm{Bu}$ nedenle firmaların mali tablolarında bulunan veriler haricinde başka herhangi bir değer yargısına 
varılamamaktadır. Bununla birlikte sadece nicel verilere dayanmayan, nitel verilerin de kullanıldığı karma marka değeri hesaplama yöntemleri genellikle özel şirketler tarafından kullanılmakta ve tam olarak metodolojisi bilinememektedir. Karma yöntemleri kullanan bu şirketlerin yapmış oldukları marka değerlendirme çalışmalarında elde ettikleri sonuçlarda da farklılıklar görülebilmektedir. Değerlendirmede kullanılan mali veriler dışında tüketici davranışlarıyla ilgili yöntemler ile ağırlık ve risk faktörlerinin göreceli olarak belirlenmesi; hem bu yöntemlerle elde edilen veriler arasında hem de finansal yöntemlerden elde edilen veriler arasında farklılıklar oluşturmaktadır.

Hirose yönteminde tamamen finansal veriler kullanılmakta olduğundan 2018 yılının firma marka değerinin hesaplanabilmesi için 2018 yılı mali verilerinin elde edilebilir olması gerekmektedir. Bununla birlikte, Brand Finance tarafından açıklanan 2018 yılı marka değeri raporu Haziran 2018 tarihinde açıklanmıştır. Brand Finance değerleme yönteminde tüm yılın finansal verilerinin kullanılmadığı anlaşılmaktadır. Hirose yöntemi ile başka firmalar için yapılan marka değerleri hesaplamalarından elde edilen sonuçlar ile, aynı firmalar için Brand Finance raporlarında açıklanan marka değerleri arasında farklılıklar olsa da yakın sonuçlar içeren çalışmalara rastlanılmıştır.

Borsa İstanbul banka sektörü çalı̧̧masında; Hirose yönteminde kullanılan mali tablo verileri, diğer akademik çalışmalarda kullanılan mali verilerden kısmen farklıdır. Bunun sebebi; banka bilançolarında, diğer şirket bilançolarında bulunan bazı muhasebe verilerinin bulunmuyor olmasıdır. Bankaların ana gelir kalemleri; faiz, ücret ve komisyonlar, gider kalemleri ise faiz giderleridir. Satışlar, yurtdışı satışlar, satılan malın maliyeti, faaliyet alanı dışındaki gelirler gibi muhasebe verileri banka bilanço ve gelir tablolarında bulunmamaktadır. $\mathrm{Bu}$ sebeple Hirose yönteminde bankalara ait mali tablo verileri Tablo 3'te verilen şekilde eşleştirilerek hesaplamalar yapılmıştır.

Hirose yönteminde kullanılan prestij değişkeni para birimi türünden bir değişken olup prestij değişkeninin formülündeki katsayılardan birisi de reklam ve promosyon gideri tutarıdır. Çalışmaya konu olan 13 bankanın mali tablolarında verilen reklam ve promosyon gider tutarları ile literatürde bulunan ve Hirose yöntemiyle marka değerleri hesaplanmış farklı sektördeki firmaların mali tablolarında bulunan reklam ve promosyon gider tutarları arasında ciddi farklılıklar bulunmaktadır. Bu durum da, Hirose yöntemi ile marka değeri hesaplanan bankacılık sektörü firmalarının marka değerlerinin, diğer sektör firmalarının aynı yöntemle hesaplanan marka değerlerine göre daha farklı olmasını açıklamaktadır.

Tüm bu bulgular ışığında gerçekleştirilen çalışma hem literatürde Hirose yönteminin yeni kullanılmaya başlanması hem de bankacılık sektöründe böyle bir gerçekleşmediği için literatüre önemli katkı sağlayacağı düşünülmektedir. Ayrıca banka marka değerlerinin sadece tek bir ölçüt olan Brand Finance raporuna göre değerlendirilmesinin yetersiz olduğunu da ortaya koymaktadır.

\section{Kaynaklar}

Aaker, D. (2018). Markalama - Başarıya Ulaştıran 20 Temel İlke (N. Özata, Çev.), Mediacat Kitapları, İstanbul.

Akgün, Ö. ve Akgün, A. (2014). Marka ve marka değeri olgusu: marka değerinin tespitine yönelik bir uygulama. Selçuk Üniversitesi Sosyal ve Teknik Araştırmalar Dergisi, 8, 1-13.

Alper, D. ve Aydoğan, E. (2017). Finansal bazlı marka değerinin firma performansı üzerine etkisi. International Journal of Academic Value Studies, 3 (16), 141-155.

Alsu, E. ve Palta, G. (2017). Marka değerinin belirlenmesi ve ölçülmesi üzerine finansal bir yaklaşım: ampirik bir çalışma. Uluslararası Afroalper-Avrasya Araştırmaları Dergisi, 4 (Aralık), 175-186.

Başçı, E. S. (2009). Marka Değerinin Tespiti ve IMKKB'de Uygulama. Doktora Tezi, Gazi Üniversitesi Sosyal Bilimler Enstitüsü, Ankara.

Brand Finance, (2018), https://brandfinance.com/ adresinden erişilmiştir (Erişim Tarihi: 01.03.2019).

Burmann, C., Benz, M.J. and Riley, N. (2009). Towards an identity-based brand equity model. Journal of Business Research, 62, 390-397.

Bursalı, O. B. (2007). Marka Değerinin Tespiti ve Denizli Tekstil Sektöründe Bir Uygulama. Gazi Üniversitesi Sosyal 
S. U. Divanoğlu - H. Bağc1 - M. Eroğlu 11/4 (2019) 2566-2577

Bilimler Enstitüsü İşletme Anabilim Dalı Muhasebe Finansman Bilim Dalı Doktora Tezi, Ankara.

Çelik, A. E. (2006). Marka değerleme. Muhasebe ve Finansman Dergisi, 31 (Temmuz), 195-208.

Demir, R. (2016). Finansal Tablo Verilerine Dayalı Marka Değeri Tespiti ve BİST Metal Eşya, Makine ve Gereç Yapım Sektöründe Uygulama. Yüksek Lisans Tezi, Başkent Üniversitesi Sosyal Bilimler Enstitüsü, Ankara.

Fischer, M. and Himme, A. (2017). The financial brand value chain: how brand investments contribute to the financial health of firms. International Journal of Research in Marketing, 34, 137-153.

Kamuyu Aydınlatma Platformu, (2019), https://www.kap.org.tr/tr/ adresinden erişilmiştir (Erişim Tarihi: 01.03.2019).

Majerova, J. and Kliestik, T. (2015). Brand valuation as an immanent component of brand value building and managing. Procedia Economics and Finance, 26, 546-552.

Min Wang, D. H. and Kuang Yu, T. H. (2015) A Fuzzy logic approach to modeling brand value: Evidence from Taiwan's banking industry. GIKA 2015: New information and communication Technologies for knowledge management in organizations, 222, 39-52.

Oliveira, M.O., Silvera, C.S and Luce, F.B (2015). Brand equity estimation model. Journal of Business Research, $68,2560-2568$.

Özkan, M. ve Terzi, S. (2012). Finansal raporlama açısından marka değerinin ölçümü ve değerlendirilmesi. Marmara Üniversitesi Sosyal Bilimler Enstitüsü Hakemli Dergisi Öneri, 10 (38), 87-96.

Öztürk, N. (2010). Marka Yönetimi. Yüksek Lisans Tezi, Kadir Has Üniversitesi Sosyal Bilimler Enstitüsü, İstanbul.

Uygurtürk, H., Uygurtürk H. ve Korkmaz T. (2017). Marka değerinin Hirose yöntemi ile belirlenmesi: BİST'te işlem gören seramik sektörü firmaları üzerine bir araştırma. International Congress of Management Economy and Policy, 20-21 Mayıs 2017-İstanbul: Bildiriler (S.10-21).

Wang, H.M. and Sengupta, S. (2016). Stakeholder relationships, brand equity, firm performance: a resourcebased perspective. Journal of Business Research, 69, 5561-5568.

Zengin, B. ve Güngördü, A. (2013). Marka değerinin hesaplanması üzerine ampirik bir çalışma: finans ve pazarlama boyutu. 12.Ulusal İssletmecilik Kongresi: 2-4 Mayıs 2013-Muğla: Bildiriler (s.283-298).

Zengin, B. ve Güngördü, A. (2015). Marka değerinin hesaplanması üzerine ampirik bir çalışma: finans ve pazarlama boyutu. Gazi Üniversitesi İktisadi ve İdari Bilimler Fakültesi Dergisi, 17 (2), 282-298. 